\title{
Advanced Control of a District Heating System with High Residential Domestic Hot Water Demand
}

\author{
Stanislav Chicherin ${ }^{1} *$ Lyazzat Junussova $^{2}$ and Timur Junussov ${ }^{2}$ \\ ${ }^{1}$ Omsk State Transport University, Russia \\ ${ }^{2}$ Almaty University of Power Engineering and Telecommunications, Kazakhstan
}

\begin{abstract}
Proper adjustment of domestic hot water (DHW) load structure can balance energy demand with the supply. Inefficiency in primary energy use prompted Omsk DH company to be a strong proponent of a flow controller at each substation. Here the return temperature is fixed to the lowest possible value and the supply temperature is solved. Thirty-five design scenarios are defined for each load deviation index with equally distributed outdoor temperature ranging from +8 for the start of a heating season towards extreme load at temperature of $-26^{\circ} \mathrm{C}$. All the calculation results are listed. If a flow controller is installed, the customers might find it suitable to switch to this type of DHW supply. Considering an option with direct hot water extraction as usual and a flow controller installed, the result indicates that the annual heat consumption will be lower once network temperatures during the fall or spring months are higher. The heat load profiles obtained here may be used as input for a simulation of a DH substation, including a heat pump and a tank for thermal energy storage. This design approach offers a quantitative way of sizing temperature levels in each DH system according to the listed methodology and the designer's preference.
\end{abstract}

\section{Introduction}

District heating (DH) systems have historically consisted of large-scale conventional production units owned by utilities. Thermal energy produced at a DH plant is transported via a branched network and is finally transferred to the consumer. This connection is commonly called a substation or an energy transfer station. However, as the knowledge and awareness of environmental problems (e.g. greenhouse gas (GHG) emission) grows, there has been a change in the approach. For instance, Malmö, Sweden is pioneering building-level facilities, creating the concept of prosumers [1] - consumers of heat that can also provide heat into the system. This has driven an energy company (1) to modernize equipment at a demand side and (2) to lower network operating temperatures, thus leading to the so called fourth generation district heating (4GDH).

On the first subject, demand side measures are measures to manipulate the load curve in a certain way through either decreasing total demand or shaping its profile in order to achieve a more suitable profile for heat supply. An action is undertaken in any part of a building HVAC system including a hydraulic or an allair installation as well as in domestic hot water (DHW) units. A successful modification may show a specific impact onto the load curve particularly peak-load shifting [2]. In turn, its benefits are cutting down installed capacity, increasing utilization of energy supply and distribution system and so improving the operational efficiency. Besides the temporal distribution, DHW structure is also a property of total load [3]. DHW structure refers to the load deviation index. The supply capacities of different types of energy may be fixed. For instance, in a network optimization nominal capacities are used $[4,5]$.

Secondly, 4GDH brings an idea of distributing heat at temperature below $45^{\circ} \mathrm{C}$ and using a heat pump at a consumer substation to provide the appropriate temperature required for space heating $(\mathrm{SH})$ and DHW production [6]. If multiple heat pumps are installed, the seasonal coefficient of performance (SCOP) of the entire system may be calculated as a weighted average of the SCOPs of the reference buildings, using the energy needs as weights [7]. It has been estimated that widespread use of a heat pump at an energy transfer station could reduce GHG by 1.25 billion tonnes over next 30 years [8].

For each desired combination of such stations in a given city, Zarin Pass et al. [9] calculate the combined hourly heating, cooling, and DHW load profiles. In Ref. [10] DHW consumption profiles were assigned based on the occupancy schedule.

Im et al. [11] present temperature profiles of a $\mathrm{DH}$ system in winter and summer. Due to heat losses in winter season, significant temperature drop of supply water occurs. In Ref. [12], authors developed an advanced thermal model for the temperature distribution along a network. As it can be seen in Ref. [13], the heat losses by assuming standard pipe parameters are higher ( $96.8 \%$ more) than the one found by assuming a constant heat transfer coefficient. The DHW is the key

Corresponding author: man_csv@hotmail.com 
component suffering from heat losses: the heat supplied can go to a heat exchanger or directly to a building extracted from supply/return pipe as more common in Russia [14]. Every heat exchanger needs a specified temperature range and thermal capacity. Once a specified temperature range is not met, direct connection cannot operate.

In comparison to previous works analyzing energy distribution, in present paper efficiency improves with increasing share of DHW supply. The aim here is to research an opportunity of an advanced control of a $\mathrm{DH}$ system with high residential DHW demand, e. g. with average DHW-SH heating ratio $\frac{Q_{\mathrm{DHW}}^{\mathrm{av}}}{Q_{\mathrm{SH}}}=0.3$.

\section{Materials \& Methods}

District heating (DH) systems have historically consisted of large-scale conventional production units owned by utilities. Thermal energy produced at a $\mathrm{DH}$ plant is transported via a branched network and is finally transferred to the consumer. This connection is commonly called a substation or an energy transfer station. However, as the knowledge and awareness of environmental problems (e.g. greenhouse gas (GHG) emission) grows, there has been a change in the approach. For instance, Malmö, Sweden is pioneering building-level facilities, creating the concept of prosumers [1] - consumers of heat that can also provide heat into the system. This has driven an energy company (1) to modernize equipment at a demand side and (2) to lower network operating temperatures, thus leading to the so called fourth generation district heating (4GDH).

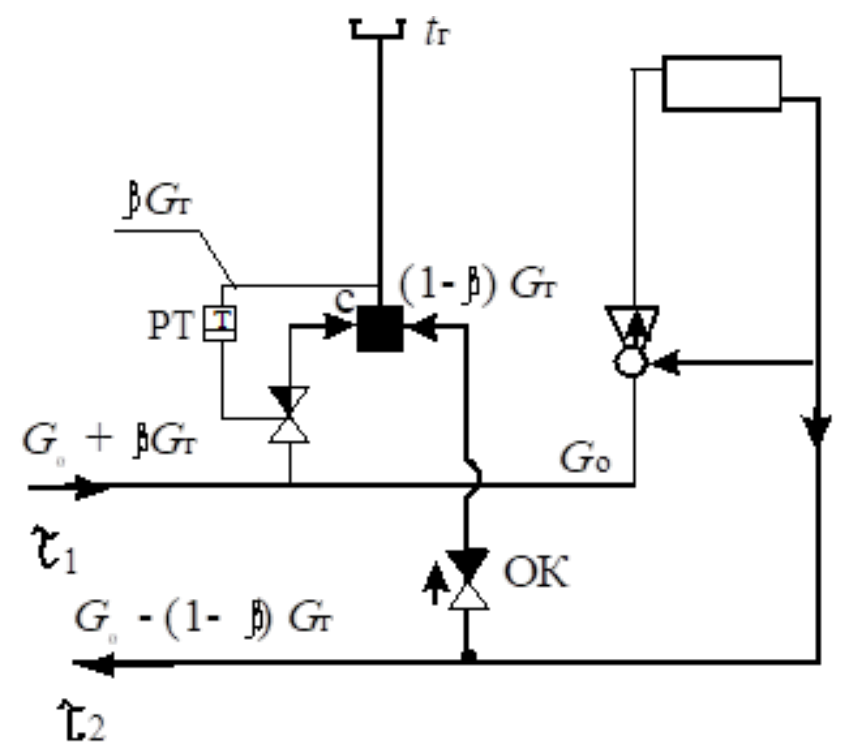

Fig. 1. Substation layout: PT temperature control valve, C mixing box, OK check valve.

Proper adjustment of DHW load structure can balance energy demand with the supply. Especially when DH or combined heat-and-power (CHP) plants are adopted, an appropriate average $\mathrm{DHW}-\mathrm{SH}$ heating ratio $\left(\frac{Q_{\mathrm{DHW}}^{\mathrm{av}}}{Q_{\mathrm{SH}}}\right)$ at a demand side can maximise the operational efficiency since this ratio determines the waste heat heat storage capacity of return water - utilization. When $\frac{Q_{\mathrm{DHW}}^{\mathrm{av}}}{Q_{\mathrm{SH}}}$ (average DHW demand to design SH demand ratio) $<0.15$, the mass flows in the $\mathrm{SH}$ pipes are almost the same as those mass flows in the corresponding DH network pipes implying an appropriate pressure drop. This creates thermal peaks, which may lead to suboptimal dispatch of CHP and heat-only boiler plants, and therefore increase fuel consumption. When a DHW-SH ratio is treated, different approaches are possible using e.g. the design value of one certain objective or a specific weighting based on an entire control strategy. In this work, as well as in Ref. [15] the way of choosing minimal outdoor temperature is used because in this case the effect of curve manipulation is better visible. The temperature profiles of the heating network, as it can be seen from Fig. 2, shows that all the return temperatures are more than or equal to the minimal value specified at DHW taps (i.e. $50^{\circ} \mathrm{C}$ ).

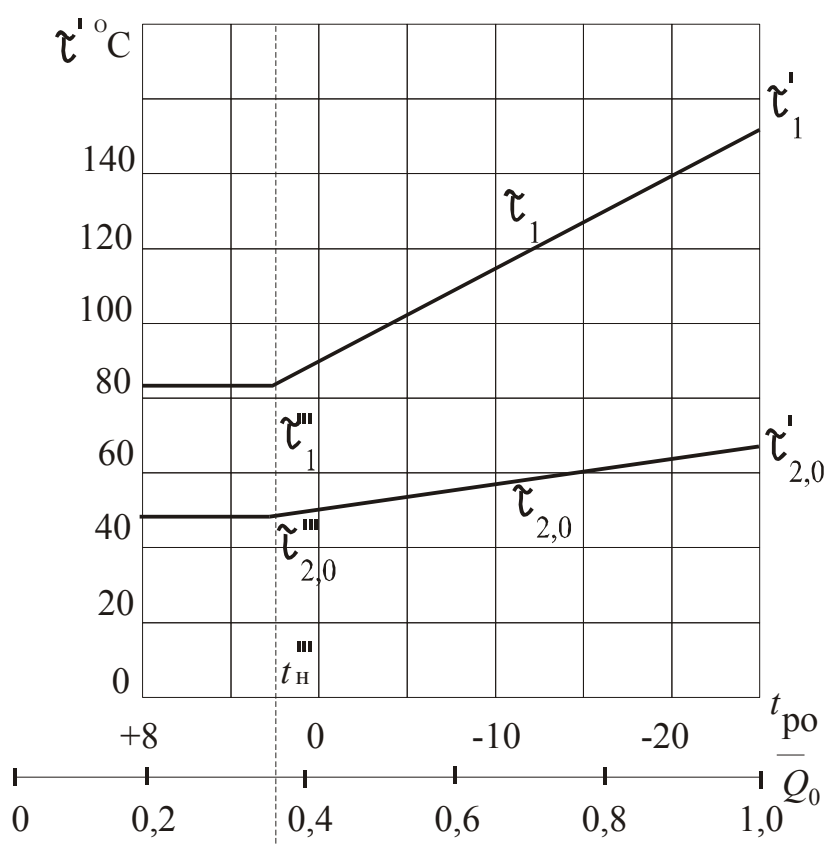

Fig. 2. Network temperatures as a function of outdoor temperature.

The supply temperature reaches its lowest value of $82^{\circ} \mathrm{C}$ when outdoor temperature is $2^{\circ} \mathrm{C}$ or above.

Design flow rate for DHW need is as follows

$$
G_{\mathrm{DHW}}=3600 \frac{Q_{\mathrm{DHW}}}{\mathrm{c}\left(t_{\mathrm{DHW}}-t_{\mathrm{t}}\right)}
$$

where $\mathrm{Q}_{\mathrm{DHW}}$ is DHW heat demand [MW], $\mathrm{c}$ is specific capacity of water $[\mathrm{kJ} / \mathrm{kgK}], \mathrm{t}_{\mathrm{DHW}}$ is DHW water temperature, and $t_{t}$ is tap water temperature. 
DHW extraction from supply line $G_{\mathrm{DHW}}^{\mathrm{s}}$ and return one $G_{\mathrm{DHW}}^{\mathrm{r}}$ can be evaluated

$$
\begin{aligned}
G_{\mathrm{DHW}}^{\mathrm{s}} & =\beta G_{\mathrm{DHW}} \\
G_{\mathrm{DHW}}^{\mathrm{r}} & =(1-\beta) G_{\mathrm{DHW}}
\end{aligned}
$$
line

where $\beta$ is a share of DHW extraction from supply

Without considering flow loss in a mixing box, the sum of all energy flowing in has to be the same as the sum of energy flowing out [16]

$$
G_{\mathrm{DHW}} t_{\mathrm{DHW}}=G_{\mathrm{DHW}}^{\mathrm{s}} \mathrm{T}_{1}+G_{\mathrm{DHW}}^{\mathrm{r}} \mathrm{T}_{2, \mathrm{o}}
$$

where $\tau_{1}$ is network supply temperature, and $\tau_{2,0}$ is network return temperature.

The share of DHW extraction from a supply line can also be acquired by Eqs. (2) and (3)

$$
\beta=\frac{t_{\mathrm{DHW}}-\mathrm{T}_{2,0}}{\mathrm{~T}_{1}-\mathrm{T}_{2,0}} .
$$

In all the cases, there is a direct correlation between DHW flow rate and ratio $\left(t_{\text {DHW }}-t_{\mathrm{t}}\right) /\left(\tau_{2,0}-t_{\mathrm{t}}\right)$, indicating that DH network return temperature does have significance for system performance. The higher the ratio applied, the better performance can be achieved. Comparing results between $\beta=0$ and $\beta=1$ simulations, one can see improved hydraulic operation whereas the temperature of return water also decreases [17].

DH network flow rate (to cover DHW need only) can be obtained as follow

$$
G_{\mathrm{DHW}}=3600 \frac{Q_{\mathrm{DHW}}}{\mathrm{c}\left(\tau_{2,0}-t_{\mathrm{t}}\right)}
$$

\section{Results \& Discussion}

DH network flow rate (to cover DHW need only) when $\tau_{2,0} \leq 60{ }^{\circ} \mathrm{C}$

$$
G_{\text {DHW }}=\frac{1.1 \cdot 55.5 \cdot 3600}{4.19(60-5)}=0.950
$$

$[\mathrm{t} / \mathrm{h}]$, and

$$
\begin{aligned}
& \text { when } \mathrm{t}_{\text {out }}=-26^{\circ} \mathrm{C} \text { and } \tau_{2,0}=70^{\circ} \mathrm{C} \\
& G_{\text {DHW }}=\frac{1.1 \cdot 55.5 \cdot 3600}{4.19(70-5)}=0.810
\end{aligned}
$$

$[\mathrm{t} / \mathrm{h}]$.

For evaluation of the technological performance of resource consumption, share of DHW extraction from supply line at an ambient temperature of $+8^{\circ} \mathrm{C}$ is determined through (5)

$$
\beta=\frac{60-32.9}{63.8-32.9}=0.875
$$

Thirty-five design scenarios are defined for each load deviation index with equally distributed outdoor temperature ranging from $+8^{\circ} \mathrm{C}$ for the start of a heating season towards extreme load at temperature of $-26^{\circ} \mathrm{C}$. All the calculation results are listed in Table 1.

In EU DH systems run with supply line water temperatures between $50-55^{\circ} \mathrm{C}$ or $60-70{ }^{\circ} \mathrm{C}$ with return line water temperatures of $25^{\circ} \mathrm{C}$ to $40{ }^{\circ} \mathrm{C}$ and still meet heating requirements for $\mathrm{SH}$ and DHW in residential or commercial buildings [8]. Im \& Liu [11] indicate that such difference between return and supply temperatures does not succeed in reaching the design temperature of SH or operating temperature of auxiliary equipment, and more heat is required from a CHP plant. Moreover, these temperature levels are not acceptable when a heat distribution network operates in Russia within the context of outdoor temperatures of -30C and below [18]. The heat load profiles obtained here may be used as input for a simulation of a $\mathrm{DH}$ substation, including a heat pump [19] and a tank for thermal energy storage [6]. It should also be mentioned that a DH operator may also vary this temperature on an annual level [20], but it is expected to be close to the suggested value [21]. The different deviation values may be accomplished by changing the ratio of loads between only-heated and DHW-supplied buildings [22].

\section{Conclusions}

Due to inefficiency, heat production price may increase over few years. One of the main reasons a DH system is appreciated by the consumers is the relatively stable $\mathrm{SH}$ and DHW prices they offer. Consequently, the increase in heat prices could lead to dissatisfaction and potential disconnections from a distribution system, further negotiating its feasibility. This design approach therefore offers a quantitative way of sizing temperature levels in each DH system according to the listed methodology and the designer's preference. It overcomes the nonoptimum design when using SH values for base load design, since the proper adjustment of DHW load structure is kept.

This research was supported by the Government of the Russian Federation under Project No. 860 (August, 292017 Decree). The Author thanks the Omsk District Heating Supply Company ('Omsk RTS', JSC) for a cooperation and kindly provided information. The author would like to acknowledge the valuable comments and suggestions of the reviewers, which have improved the quality of this paper. The author also expresses gratitude to Raoul Karimov who has proof-read and edited the text. 
Table 1. Results of the temperature and flow analysis

\begin{tabular}{|c|c|c|c|c|c|c|c|c|c|c|c|c|c|}
\hline $\begin{array}{l}t_{\text {out }} \\
{\left[\left[^{\circ} \mathrm{C}\right]\right.}\end{array}$ & $Q_{\mathrm{o}}$ & $G_{\mathrm{o}}$ & $\begin{array}{l}\tau_{1, \mathrm{o}} \\
{\left[^{\circ} \mathrm{C}\right]}\end{array}$ & $\begin{array}{l}\tau_{2, \mathrm{o}} \\
{\left[{ }^{\circ} \mathrm{C}\right]}\end{array}$ & $\begin{array}{c}\tau_{1} \\
{\left[^{\circ} \mathrm{C}\right]}\end{array}$ & $\begin{array}{c}\tau_{2} \\
{\left[{ }^{\circ} \mathrm{C}\right]}\end{array}$ & $\beta$ & $\begin{array}{c}G_{\mathrm{SH}} \\
{[\mathrm{t} / \mathrm{h}]}\end{array}$ & $\begin{array}{c}G_{\mathrm{DHW}} \\
{[\mathrm{t} / \mathrm{h}]}\end{array}$ & $\begin{array}{c}G_{\mathrm{DHW}}^{s} \\
{[\mathrm{t} / \mathrm{h}]}\end{array}$ & $\begin{array}{c}G^{r} \mathrm{DHW} \\
{[\mathrm{t} / \mathrm{h}]}\end{array}$ & $\begin{array}{c}G_{1} \\
{[\mathrm{t} / \mathrm{h}]}\end{array}$ & $\begin{array}{c}G_{2} \\
{[\mathrm{t} / \mathrm{h}]}\end{array}$ \\
\hline 1 & 2 & 3 & 4 & 5 & 6 & 7 & 8 & 9 & 10 & 11 & 12 & 13 & 14 \\
\hline 8 & 227 & .582 & 53.1 & 4.9 & 64.1 & 32.8 & 0.87 & 1.157 & .954 & 0.830 & .124 & .987 & 1.033 \\
\hline 7 & 250 & 618 & 56.2 & 62 & 56 & 4.2 & 0.80 & .227 & 954 & 759 & 194 & 987 & .033 \\
\hline 6 & 273 & 650 & 59.2 & 37.4 & 69.1 & 35.6 & 0.73 & 1.292 & 954 & 695 & 259 & 987 & 1.033 \\
\hline 5 & 0.295 & 0.681 & 62.3 & 38.6 & 71.6 & 36.9 & 0.67 & 1.352 & 954 & 635 & .319 & 987 & .033 \\
\hline 4 & 0.318 & 0.709 & 65.3 & 39.8 & 74.1 & 38.2 & 0.61 & 1.408 & 0.954 & 0.579 & .375 & 987 & 1.033 \\
\hline 3 & 0.341 & 0.735 & 68.3 & 41.0 & 76.6 & 39.5 & 0.55 & 1.459 & 0.954 & 0.527 & .426 & 987 & 1.033 \\
\hline 2 & 0.364 & 0.759 & 71.3 & 42.2 & 79.1 & 40.7 & 0.50 & 1.507 & & 479 & & & .033 \\
\hline 1 & 386 & 0.781 & 74.2 & 43. & 81.5 & 42.0 & 0.46 & 1.552 & - & 435 & 519 & 87 & 1.033 \\
\hline 0 & 109 & 302 & 77.2 & 4 & 84.0 & 43.2 & 0.41 & 594 & & & & & 033 \\
\hline-1 & 432 & 322 & 80.1 & 45. & 86. & 44.4 & 0.37 & 1.632 & 954 & 354 & 599 & 87 & 1.033 \\
\hline-2 & 0.455 & 0.840 & 83.0 & 46.6 & 88.9 & 45.6 & 0.33 & 1.669 & 954 & 318 & 636 & 987 & 1.033 \\
\hline-3 & 0.477 & 0.857 & 85.9 & 47.7 & 91.3 & 46.7 & 0.30 & 1.703 & 0.954 & 284 & .670 & 987 & 1.033 \\
\hline-4 & 0.500 & 0.873 & 88.8 & 48.8 & 93.7 & 47.9 & 0.26 & 1.735 & 0954 & 252 & .702 & 87 & 1.033 \\
\hline-5 & 0.523 & 0.888 & 91.7 & 49.9 & 96.1 & 49.0 & 0.23 & 1.765 & & & & & 033 \\
\hline-6 & 0.545 & 0.902 & 94. & 50 & 98 & 50.2 & 0.20 & 3 & & & & & 33 \\
\hline-7 & 68 & 0.916 & 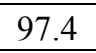 & 51 & -2 & 51.3 & 0.18 & 1.819 & & & & & .033 \\
\hline-8 & 591 & 0.928 & 100.2 & 53. & 10 & 52.4 & 0.15 & 1.844 & & 143 & & & .033 \\
\hline-9 & 0.614 & 0.940 & 103.1 & 54.0 & 105.7 & 53.5 & 0.12 & 1.868 & 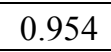 & 119 & 835 & 87 & 1.033 \\
\hline-10 & 0.636 & 0.951 & 105.9 & 55.0 & 108.1 & 54.6 & 0.10 & 1.890 & 0 & 097 & 857 & 87 & 1.033 \\
\hline-11 & 0.659 & 0.962 & 108.7 & 56.0 & 110.5 & 55.6 & 0.08 & 1.911 & & 0.076 & 0.878 & 37 & 1.033 \\
\hline-12 & 0.682 & 0.972 & 111.5 & 57.0 & 112.8 & 56.7 & 0.06 & 1.931 & & 56 & & 37 & 1.033 \\
\hline-13 & 0.705 & & & & & & & & & & & & \\
\hline-14 & 0.727 & 0.990 & 117 & 58 & 117 & 58.8 & 0.02 & 1.968 & & 9 & & 7 & 1.033 \\
\hline-15 & 0.750 & 0.999 & 119 & 59. & $11 \mathrm{C}$ & 59.9 & 0.00 & 1.985 & 0 & 02 & 1 & 37 & .033 \\
\hline-16 & 0.773 & 1.000 & 122.6 & 60.8 & 122.6 & 60.8 & 0.00 & 1.987 & 0.940 & 00 & 40 & 37 & 1.047 \\
\hline-17 & 0.795 & 1.000 & 125.4 & 61.8 & 125.4 & 61.8 & 0.00 & 1.987 & 0.924 & 0.000 & 0.924 & 1.987 & 1.063 \\
\hline-18 & 0.818 & 1.000 & 128.2 & 62.7 & 128.2 & 62.7 & 0.00 & 1.987 & 0.90 & 0.000 & 0.909 & 1.987 & 1.078 \\
\hline-19 & 0.841 & 1.000 & 130.9 & 63. & 130.9 & 63.6 & 0.00 & 1.987 & 80 & 0.000 & 95 & 37 & 1.092 \\
\hline-20 & 0.864 & 1.000 & 133 & & & 64.6 & & & & & & & 1.106 \\
\hline-21 & 0.886 & 1.000 & 136.4 & 65. & 136 & 65.5 & 0.00 & 1.987 & 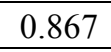 & 00 & 67 & 87 & 1.120 \\
\hline-22 & 0.909 & 1.000 & 139.1 & 66.4 & 139.1 & 66.4 & 0.00 & 1.987 & 005 & 0.000 & 0.854 & 1.987 & 1.133 \\
\hline-23 & 0.932 & 1.000 & 141.9 & 67.3 & 141.9 & 67.3 & 0.00 & 1.987 & 0.842 & 0.000 & 0.842 & 1.987 & 1.145 \\
\hline-24 & 0.955 & 1.000 & 144.6 & 68.2 & 144.6 & 68.2 & 0.00 & 1.987 & 0.830 & 0.000 & 0.830 & 1.987 & 1.157 \\
\hline-25 & 0.977 & 1.000 & 147.3 & 69.1 & 147.3 & 69.1 & 0.00 & 1.987 & 0 & 0.000 & 18 & 1.987 & 1.169 \\
\hline-26 & 1.000 & 1.000 & 150.0 & 70.0 & 150.0 & 70.0 & 0.00 & 1.987 & 0.807 & 0.000 & 0.807 & 1.987 & 1.180 \\
\hline
\end{tabular}

\section{References}

1. Brange, L., Englund, J. \& Lauenburg, P. Prosumers in district heating networks - A Swedish case study. Appl. Energy 164, 492-500 (2016).

2. Guelpa, E., Barbero, G., Sciacovelli, A. \& Verda, V. Peak-shaving in district heating systems through optimal management of the thermal request of buildings. Energy 137, 706-714 (2017).

3. Hou, J. et al. Implementation of expansion planning in existing district energy system: A case study in China. Appl. Energy 211, 269-281 (2018).
4. Tunzi, M., Boukhanouf, R., Li, H., Svendsen, S. \& Ianakiev, A. Improving thermal performance of an existing UK district heat network: A case for temperature optimization. Energy Build. 158, 15761585 (2018).

5. Delangle, A., Lambert, R. S. C., Shah, N., Acha, S. \& Markides, C. N. Modelling and optimising the marginal expansion of an existing district heating network. Energy 140, 209-223 (2017).

6. Vivian, J. et al. Evaluating the cost of heat for end users in ultra low temperature district heating 
networks with booster heat pumps. Energy (2018). doi:10.1016/j.energy.2018.04.081

7. Junussova, L. R., Abildinova, S. K., Aliyarova, M. B., Chicherin, S. V. \& Junussov, T. J. The means to improve water treatment and to enhance power engineering performance of the water source heat pump. Energ. Proc. CIS High. Educ. Institutions Power Eng. Assoc. 61, 372-380 (2018).

8. Sayegh, M. A. et al. Heat pump placement, connection and operational modes in European district heating. Energy Build. 166, 122-144 (2018).

9. Zarin Pass, R., Wetter, M. \& Piette, M. A. A thermodynamic analysis of a novel bidirectional district heating and cooling network. Energy 144, 20-30 (2018).

10. Andrić, I., Fournier, J., Lacarrière, B., Le Corre, O. \& Ferrão, P. The impact of global warming and building renovation measures on district heating system techno-economic parameters. Energy (2018). doi:10.1016/j.energy.2018.03.027

11. Im, Y.-H. \& Liu, J. Feasibility study on the low temperature district heating and cooling system with bi-lateral heat trades model. Energy 153, 988-999 (2018).

12. Wang, H., Meng, H. \& Zhu, T. New model for onsite heat loss state estimation of general district heating network with hourly measurements. Energy Convers. Manag. 157, 71-85 (2018).

13. Ayele, G. T., Haurant, P., Laumert, B. \& Lacarrière, B. An extended energy hub approach for load flow analysis of highly coupled district energy networks: Illustration with electricity and heating. Appl. Energy 212, 850-867 (2018).

14. Chicherin, S. Low-temperature district heating distributed from transmission-distribution junctions to users: energy and environmental modelling. Energy Procedia 147, 382-389 (2018).

15. Chicherin, S., Junussova, L. \& Junussov, $T$. Minimizing the supply temperature at the district heating plant - dynamic optimization. E3S Web Conf. 118, (2019). doi:10.1051/e3sconf/201911802004

16. Abdikarimov, M. N., Turgumbayeva, R. K., Sagintaeva, S. S., Mussabekov, R., \& Abildinova, S. K. (2019). Heatfireprotection Polymer Coatings on the Basis of EPDM-40 with Additives. Key Engineering Materials, 816, 356-361. doi:10.4028/www.scientific.net/kem.816.356.

17. Belilovets, V. I., \& Lipovka, Y. L. (2018). DESIGNING UNDERGROUND TRENCHLESS THERMALLY PRE-STRESSED HEAT SUPPLY PIPELINES WITH EXPANSION JOINTS. BULLETIN OF THE TOMSK POLYTECHNIC UNIVERSITY-GEO ASSETS ENGINEERING, 329(7), 57-69.

18. Chicherin, S., Volkova, A. \& Latõšov, E. GIS-based optimisation for district heating network planning. Energy Procedia 149, 635-641 (2018).

19. Junussova, L. \& Chicherin, S. Improving a water treatment and a heating performance of the water-towater heat pump: misallocation and available solutions. IOP Conf. Ser. Earth Environ. Sci. 288, 12092 (2019). doi:10.1088/1755-1315/288/1/012092

20. Junussova, L. R. \& Chicherin, S. V. Method of Aluminum Salts Extraction from Wastewater Using Desalination Technology: Syr Darya River Case Study. IOP Conf. Ser. Earth Environ. Sci. 288, 012008 (2019). doi:10.1088/1755$1315 / 288 / 1 / 012008$

21. (Thanos) Bourtsalas, A. C., Seo, Y., Tanvir Alam, M. \& Seo, Y.-C. The status of waste management and waste to energy for district heating in South Korea. Waste Manag. 85, 304-316 (2019).

22. von Rhein, J., Henze, G. P., Long, N. \& Fu, Y. Development of a topology analysis tool for fifthgeneration district heating and cooling networks. Energy Convers. Manag. 196, 705-716 (2019). 